\title{
DEFINIENDO HOMO SAPIENS-SAPIENS: APROXIMACIÓN ANTROPOLÓGICA
}

\section{Carolina Valdebenito*}

Resumen: Este artículo reflexiona sobre los encuentros y desencuentros entre el ser humano y el resto de los animales, en tanto miembros de sistemas en permanente interacción(1).

Abordar la definición de Homo, repasar su evolución biológica y cultural y reflexionar sobre los resabios de animalidad que quedan en el comportamiento social del Homo sapiens-sapiens es su objetivo principal. Se busca reflexionar sobre los dilemas morales que acompañan al hombre en tanto ser cultural; para ello se analizan dos dilemas éticos: la violencia y el incesto.

Palabras clave: antropología, ser humano, animal, violencia, incesto

\section{DEFINING HOMO SAPIENS-SAPIENS: ANTHROPOLOGICAL APPROACH}

Abstract: This paper reflects on the similarities and differences between human beings and animals as members of systems in permanent interaction.

The main goal is to define Homo, reviewing his/her biological and cultural evolution and reflecting on the animal social behaviors that still remain in Homo sapiens-sapiens. The paper reflect on the moral dilemmas present in humans as cultural beings, taking as example the ethical dilemmas of violence and incest.

Key words: anthropology, human being, animal, violence, incest

\section{DEFININDO HOMO SAPIENS-SAPIENS: APROXIMAÇÃO ANTROPOLÓGICA}

Resumo: Este artigo reflete sobre os encontros e desencontros entre o ser humano e os demais animais, enquanto membros de sistemas em permanente interação(1). Seu principal objetivo é abordar a definição de Homo, traçar um panorama de sua evolução biológica e cultural e refletir sobre os resquícios da animalidade que permanecem no comportamento social do Homo sapiens-sapiens. Busca-se refletir sobre os dilemas morais que acompanham o homem enquanto ser cultural, o que para isso são considerados como dilemas éticos: a violência e o incesto.

Palavras chave: antropologia, ser humano, animal, violência, incesto

* Antropóloga Social, Magíster en Salud Pública. Colaboradora del Centro Interdisciplinario de Estudios en Bioética de la Universidad de Chile, Chile

Correspondencia: carvaldeb@uchile.cl 


\section{¿Qué es el Homo sapiens-sapiens?}

La figura 1 muestra de manera simple el curso que ha seguido la evolución humana.

Figura 1

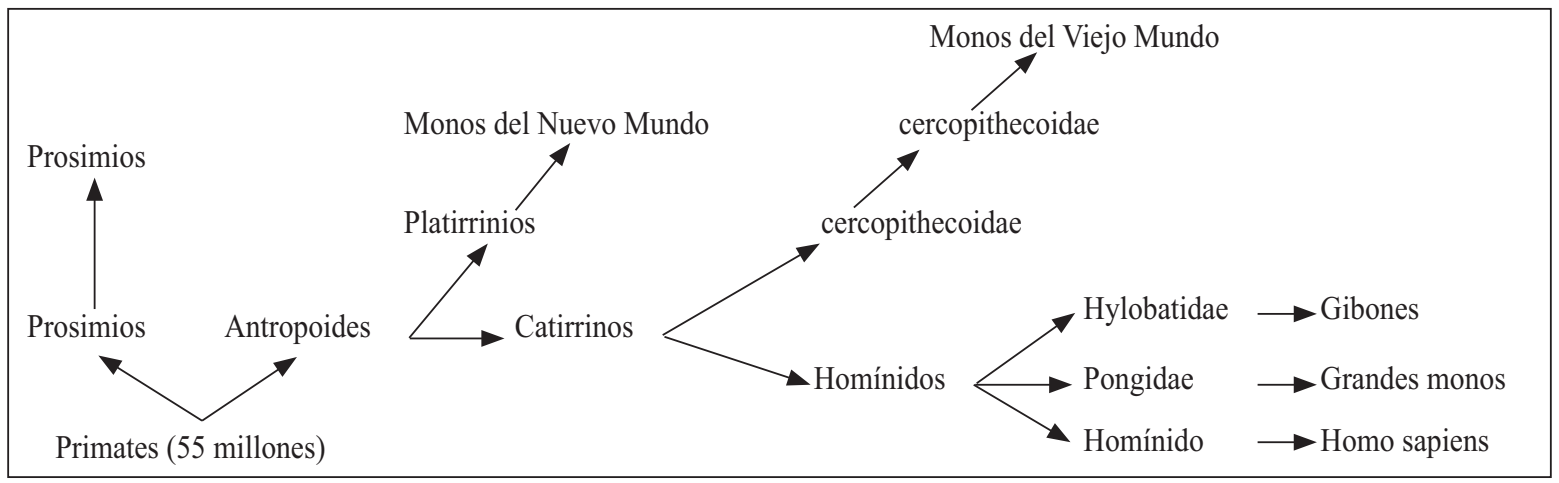

Lo que se quiere señalar con esto es el origen animal del hombre. El registro fósil indica que los primates evolucionaron hace unos 3055 millones de años en África(2). Las ramas evolucionadas de los primates fueron los monos. A su vez, el primer homínido conocido es Australopithecus afarensis, similar al humano actual, que apareció hace unos tres a cuatro millones de años(2).

Hay especialistas que establecen una taxonomía entre los pongidae y los homínidos en términos de familia, mientras que otros prefieren hablar de una separación en el plano de la especie. Ello podría, eventualmente, tener alguna implicancia moral en el estatus que se otorga al ser humano.

Las características de los primates son su complejidad cortical, el desarrollo de su visión estereoscópica y la sociabilidad de la especie. Desde hace cuatro millones de años los homínidos se definen por su bipedismo. Sus piernas son más largas y fuertes que sus brazos, a diferencia de los monos, dado que sobre ellas deben sostener su cuerpo en equilibrio. A su vez, dejar las manos libres les ha permitido desarrollar el sentido del tacto y manipular objetos.

Dentro de los homínidos es posible distinguir el siguiente cuadro evolutivo

Australopithecus ramidus
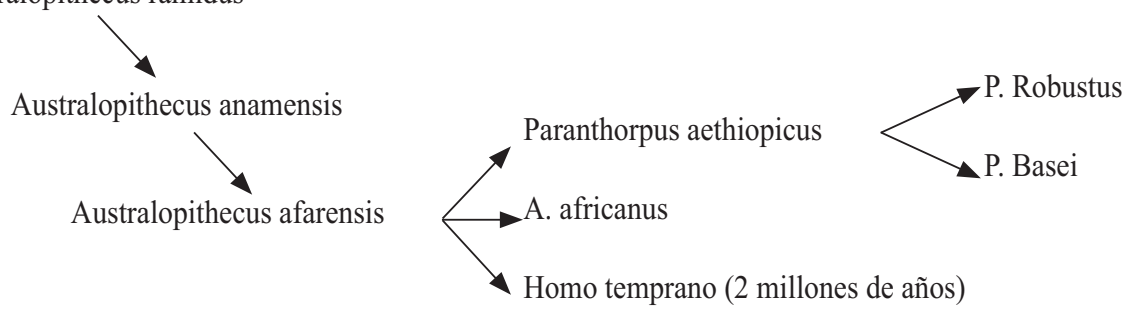

Homo habilis

Homo ergaster

Homo erectus

Homo antecesor

Homo neanderthalensis

Homo sapiens 
Hace 1,8 millones de años los primeros homos dan paso al Homo erectus, especie que se considera el ancestro directo del ser humano moderno. El Homo erectus difiere de las primeras especies por tener un cerebro de mayor tamaño, rostro plano y arco superciliar prominente(2).

Lo destacable de este homínido radica en que fue el primero que dejó vestigios culturales y sociales de la evolución humana (uso del fuego), y tuvo una estructura social destinada a la recolección de alimentos; también utilizaba asentamientos permanentes y dedicaba un prolongado período al acompañamiento de los hijos luego del nacimiento.

A partir de los prosimios primitivos se producirá la separación entre los prosimios propiamente tales (lémur, lori) y los antropoides (platirrinios, catarrinos, gibón, orangután, gorila, chimpancé). De la rama de los grandes simios descenderá el Homo(2).

Anatómicamente, el hombre moderno es clasificado como Homo sapiens-sapiens. Apareció hace 120.000-100.000 años asociado al desarrollo tecnológico. No está clara su relación con el Neandertals, pero se sabe que fue contemporáneo. Comparado con éste y con el Homo sapiens arcaico, el sapiens-sapiens tenía un esqueleto más delicado, sus huesos eran más redondeados y tenía menos protuberancia frontal(2).

En la evolución desde los prosimios al Homo sapiens-sapiens habrían incidido la presión ambiental, el cambio de clima, la desglaciación y glaciación y el cambio de flora y fauna(2).

Pero no sólo se dieron cambios biológicos, como el bipedismo o la visión estereoscópica -que ya poseían siendo descendientes de los primates-, también se produjeron procesos culturales que provocaron diferencias entre el
Homo y el resto de los animales, aun cuando vinieran de un mismo origen.

\section{Cultura y aprendizaje}

De acuerdo con el recorrido antropológico del hombre, parece condición sine qua non referirnos a la cultura como factor determinante de la condición de persona humana.

Una definición clásica de cultura la concibe como todo lo que es hecho o intervenido por el hombre. Es todo: materialidad, creencias, ideas, etc.(3). Y entre sus aspectos más importantes destaca la comunicación. Por su parte, naturaleza, siguiendo a Lévi-Strauss(4), se entiende como todo aquello que no ha sido intervenido por el hombre, todo lo que no guarda, en sí, valoración alguna.

Uno de los aspectos que más controversia suscita para distinguir entre naturaleza y cultura es la comunicación. Si se la comprende como el proceso de transferencia de información desde un emisor a un receptor(5), no parece haber mayor diferencia entre el proceso que establecen los animales y el que realizan los seres humanos. Sin embargo, el contraste parece estar en el mensaje, en su contenido valórico, en los filtros y transformaciones que sufre en el proceso comunicativo, es decir, el paso del emisor al receptor modifica el mensaje y, a su vez, modifica a los emisores y receptores(6).

El proceso de comunicación humana es también un proceso de representación y construcción de la realidad, y es acompañado de toda la historia, experiencia y representaciones previas de emisor y receptor. La comunicación humana es más que el proceso lineal de transmitir una información pragmática que puede permitir, por ejemplo, la sobrevivencia de la especie. Es un proceso social de construcción y de-construcción de la realidad(7). 
La comunicación humana se puede señalar como rasgo cultural en tanto no sólo se produce vía vocal-auditiva, sino que involucra también el lenguaje kinésico y proxémico ${ }^{1}$. Para interpretar los mensajes transmitidos se necesita conocer códigos de de-codificación o de-construcción del mensaje. Por lo tanto, vemos otra diferencia con la comunicación animal: ésta es universal a su especie, es decir, no importa la consanguinidad o línea de parentesco o idioma; frente al peligro o a la misma necesidad - como pueden ser la caza o la huida-el mensaje parece unívoco. En cambio, en el ser humano la interpretación del mensaje debe ser filtrada por códigos comprehensibles entre emisor y receptor. El ejemplo más simple de ello es el idioma: no es posible establecer una conversación entre personas si no existe un conocimiento compartido del idioma en el cual se transmitirán los mensajes.

Mayor complejidad aporta el marco cultural en el cual se interpretan los códigos y mensajes emitidos y recibidos. Está constituido por las costumbres, valores, hábitos y creencias. Es el contexto que permite entender, aprehender e interpretar acertadamente el significado de un mensaje, aun cuando éste no se trasmita mediante la vía vocal-auditiva. Por otra parte, no compartir el entramado cultural puede producir malos entendidos o conflictos sociales.

Para que sea exitoso, el proceso de comunicación debe ir unido al de aprendizaje, es decir, el sentido del mensaje y la forma de interpretarlo deben compartir patrones comunes. Sin embargo, algunos estudios sostienen que en la comunicación animal también hay complejidades.

\section{Comunicación y aprendizaje}

Lorenz realizó estudios comparativos de comportamiento; comprendió que el aprendizaje produce conductas de adaptación y que

1 Kinésica: lenguaje corporal. Proxémica: área que ocupa una persona más allá del cuerpo. eso tendría una connotación innata. Skinner desarrolló la filosofía del conductismo radical y el análisis del comportamiento aplicado, una rama de la psicología que tiene como objetivo un trabajo unitario para animales y humanos basado en el aprendizaje. Experimentó a través de reforzamiento negativo $\mathrm{y}$ positivo $\mathrm{y}$ demostró que el condicionamiento es una técnica de modificación de conducta. Uno de sus experimentos más destacados fue con palomas hambrientas a las que encerró en una jaula. Ésta tenía un mecanismo automático que les daba comida a las palomas de manera regular. La hipótesis de Skinner es que la actividad que la paloma estuviera realizando en el momento de recibir la comida, sería la actividad que la paloma continuaría haciendo. Lo que descubrió Skinner fue una cierta superstición por parte de las aves que asociaron su comportamiento con la comida. Este experimento sorprende a la hora de comparar los comportamientos social-humanos con los que presentan los animales.

Otro ejemplo es el relativo al comportamiento condicionado que Pavlov observa en un perro. Pavlov constató que el animal salivaba cuando la comida aún no llegaba a su boca; también que salivaba igualmente ante la presencia de quien le acercaba la comida. Luego probó tocando una campanilla cada vez que al animal se le daba comida. Luego de algunos intentos, tocó la campanilla sin darle comida y se dio cuenta que el perro salivaba de igual forma, es decir presentaba un comportamiento condicionado.

Si los animales tienen comunicación y aprendizaje, ¿cuál es entonces su diferencia respecto de los seres humanos? Nuevamente, la comunicación y el aprendizaje que probaron los etólogos en animales es un tipo de aprendizaje y socialización vicarios ${ }^{2}$ o de sobrevivencia,

2 Desarrollado por Albert Bandura, es un modelo muy evolucionado de conductismo que sostiene que es posible aprender conductas siguiendo modelos observados en otros con los que uno se identifica, sin necesidad de práctica. 
mientras que la comunicación humana está basada en patrones culturales que permiten la interpretación de los códigos compartidos.

Si bien los animales tienen habilidades sociales -conductas basadas en el dominio de habilidades de comunicación, esto es, emitir y recibir mensajes y saber descifrarlos en forma asertiva, de manera de lograr una transmisión exitosa-, el propósito de la comunicación es algo que forma parte del proceso: se comunica para alcanzar alimento, para advertir un peligro, para aparearse, para correr, para jugar. La comunicación humana, sin embargo, puede pensarse a sí misma en un proceso de metaobservación que no sería posible en otras especies.

Un grupo de abejas, una manada de caballos o lobos tienen, sin duda, formas de comunicación que hacen viable la vida gregaria, sobre todo en ambientes adversos donde existe escasez de recursos. A su vez, que la hembra puma enseñe a sus cachorros a cazar es prueba de un aprendizaje vicario que deberán poner en práctica a diario para la sobrevivencia, pero no refleja una interpretación simbólica de la realidad.

La comunicación humana no sólo tiene un propósito de sobrevivencia gregaria, sino de representación de la realidad a través del pensamiento abstracto y significación simbólica. El ser humano piensa y luego se crea y se representa, y entonces existe. Conocida es la sentencia cogito ergo sum, pienso luego existo. El hombre es el único ser que tiene conciencia de su existencia y, en tanto la tiene, es posible su ser.

Si entendemos al ser humano como ser pensante, que conoce la realidad en tanto la experimenta y la conceptualiza, el peso de la cultura y, por tanto, de la comunicación se vuelve fundamental. Solo habrá construcción de realidad y elaboración de cultura en tanto haya un sistema de comunicación con los elementos suficientes para transmitir los significantes y significados(7) y se genere un entramado que acompañe todas las acciones humanas.

\section{Ser persona}

La noción de "persona" se encuentra en constante construcción. En este proceso de construcción y metaobservación que realiza el hombre se rescata el estatus inmortal que se ha atribuido a sí mismo través del concepto de alma, constructo basado en la articulación compleja de religiones, mitos y leyendas desarrollados desde los inicios del Homo cultural y como explicación conceptual de los fenómenos que le rodean.

En lo que Nietzsche llama la incapacidad humana de perecer o de hacerse responsable de sí mismo, en esa situación de permanente escapatoria de la mortalidad, de la carne, de lo perecedero, es que surge la persona como ser excepcional. La sacralización de su ser reviste al humano de un carácter especial y lo distingue de los demás animales (sin olvidar que es también animal).

¿Cuándo somos persona? ¿En el momento de la fecundación? ¿En el estado de embrión o feto? ¿En el alumbramiento o cuando comenzamos a pensarnos a nosotros mismos? ¿Somos persona en tanto somos humanos?

¿Qué sucede con los discapacitados mentales? ¿Con los niños? ¿Con los nonatos? ¿Acaso no forman parte de la especie humana? Cuando se muere, ¿se deja de ser humano? ¿Qué sucede con el alma?

\section{Perspectivas de lo humano}

Los hombres no siempre han aludido al alma para afirmar su condición superior frente a las demás especies de mamíferos. Es más, durante el siglo XVIII el utilitarismo da buenas razones 
para encontrar similitudes entre el ser humano y los demás animales, destacando la necesidad de placer y bienestar que ambos comparten.

Los especieistas no están de acuerdo en la supremacía de la especie humana por sobre las otras especies. Por oposición, el personalismo resalta la capacidad de abstracción y, por tanto, de autoconciencia del ser humano, lo que lo distingue de otras especies.

En este proceso de pensar-se y re-conocerse a sí mismo como distinto a otro tienen gran importancia el entorno social, familiar, ambiental, histórico, político y económico. Somos producto de nuestro tiempo y contexto, y es en relación con éste que se van formando nuestras valoraciones, redes comunicativas, significados y significantes.

Es en los primeros años de vida donde el ser humano totipotencial adquiere las formas o categorías conceptuales con las cuales llegará a comunicarse, interpretar y conocer su realidad.

\section{Violencia e incesto: ¿resabios de animalidad?}

En este artículo se entenderá como animalidad lo propio de los animales y de la naturaleza que no ha sido modificado, valorado ni sometido a valoración humana.

\section{Violencia}

La violencia individual puede ser definida, de acuerdo con Girard, como un proceso de inculpación e identificación de un chivo expiatorio, a través del cual se canaliza la violencia intestina de los sistemas sociales. Es decir, cuando una sociedad o grupo humano presenta un problema o vive una crisis se busca a un culpable, que suele ser un extranjero-cercano, alguien que es parcialmente aceptado como miembro de la sociedad pero suficientemente extranjero como para culparlo de las desgracias del grupo. Luego de identificado y culpado, se sacrifica, se mata al chivo expiatorio y con ello termina la crisis del grupo.

Desde entonces, en adelante $-\mathrm{y}$ para no volver a vivir la crisis- se conmemorará el sacrificio de la víctima, de modo de evitar el caos que implicó matarla así como el problema que trajo su existencia. La víctima será entonces sacralizada $(8)$.

Según Ricoeur, la violencia se produce en la crisis mimética, esto es, cuando hay pérdida de identidad. La falta de identidad genera caos, angustia, miedo; por tanto, se establece la diferencia a través de la violencia y la muerte(9).

Muchas organizaciones, entre ellas las feministas y femeninas, reclaman sus derechos contra la violencia intrafamiliar que, mayoritaria pero no exclusivamente, afecta a la mujer. Es usual oír que la violencia no es natural y que por ello se debe erradicar. Sin embargo, la violencia tal como lo muestran los estudios en animales y en comportamiento humano, es natural y no cultural.

Si seguimos a Girard, podemos decir que la violencia intrafamiliar se produce cuando hay una crisis sistémica y se culpa al que, perteneciendo a la familia, sigue siendo extranjero, esto es, la mujer. Ella ha dejado su techo paterno para unirse a la familia del esposo, en una suerte de "moneda de intercambio", como se hacía en las sociedades patrilineales donde la mujer era usada para establecer alianzas entre familias, clanes, tribus, en una forma de garantizar la cooperación.

No sería difícil aplicar esta teoría en Latinoamérica, considerando la preponderancia del apellido paterno (excepto algunos países como Brasil), o donde aún se usa que la familia de la novia "pague la fiesta" de matrimonio como 
una especie de "dote" y que sea ella quien se va "siguiendo" al marido.

De acuerdo con Ricoeur, en cambio, podríamos decir que la violencia intrafamiliar en las sociedades modernas se debe a la falta de diferenciación entre el hombre y la mujer, ambos trabajan, ambos son altamente competitivos y no hay una definición clara de roles, sino una suerte de complementación casuística.

De cualquier manera, esta forma de resolver los conflictos es un "reflejo", o lo que algunos llamarían "instinto"4 animal sine qua non de nuestros antecedentes prosimiescos.

La penalización, el asco y estupor que nos produce la violencia es una construcción cultural debido a la observación de la humanidad contra los abusos cometidos. Tal como Hobbes señala, siendo la naturaleza del hombre el conflicto y la violencia, cedemos nuestra capacidad de violencia, entregamos nuestra resolución -a través de la agresión- a un tercero, de manera que el sistema social no se destruya a sí mismo(10).

Si somos quienes creemos ser y fundamos nuestros gobiernos y reglas para regular y mantener un equilibrio sistémico, ¿por qué se sigue utilizando la violencia como medio de resolver los conflictos?

3 El reflejo es una pauta hereditaria de comportamiento, común a toda una especie, pero, a diferencia del instinto, es de carácter local (no compromete a todo el organismo sino a una pequeña parte de éste) y no asegura la supervivencia del individuo.

4 El instinto es una pauta hereditaria de comportamiento universal y las excepciones y variabilidad son mínimas, explicándose por el instinto mismo. Posee finalidad adaptativa y de supervivencia, y un objeto específico y fijo. Es de carácter complejo, es decir, consta de una serie de pasos para su producción: percepción de la necesidad, búsqueda del objeto, percepción del objeto, utilización del objeto, satisfacción y cancelación del estado de necesidad. Es global: compromete a todo el organismo vivo.

\section{Incesto}

Lévi-Strauss(4) concluyó que la proscripción del incesto no es natural. Ello significa que la prohibición de mantener relaciones sexuales con alguien no pertenece al ámbito de la naturaleza, no hay una consecuencia biológica inmediata, un "castigo divino" sobre las personas que cometen incesto. En estricto rigor, Lévi-Strauss señala que "no pasa nada".

Usualmente vemos animales teniendo relaciones sexuales entre padres/hijas, madres/hijos, hermanos, etc., pues no hay remembranza de su consanguinidad, no hay filiación afectiva ni redes de cooperación ni de comunicación simbólica, como sí sucede en la cultura humana.

Muchas castas y monarquías han mantenido una línea de filiación endogámica más que exogámica, lo que ha traído defectos genéticos en los descendientes cuando la endogamia es estricta, pues hay poca variabilidad de genes (la variedad permite la resistencia, sobrevivencia y adaptación).

Lévi-Strauss señala que la prohibición del incesto, es decir, el impedimento para tener relaciones sexuales con cierto tipo de personas, es fundamentalmente cultural y que con esta prohibición aparece la cultura como el elemento que diferencia al ser humano del resto de los animales. Antes del establecimiento del incesto no habría discriminación, todo era posible y permitido, el sexo, al igual que en los animales, sólo constituía una necesidad biológica que satisfacer. Pero cuando el ser humano define con qué personas tendrá sexo y con quienes no, entonces se produce la separación moral entre Homo sapiens-sapiens y animal: el hombre, como ser moral, tiene la capacidad de distinguir entre el ser y el deber ser.

La aparición de la prohibición del incesto dentro del grupo familiar se debería a la nece- 
sidad de establecer alianzas con otras familias, de manera de cooperar mutuamente frente a las mismas necesidades y a un entorno hostil, facilitando la transmisión cultural.

\section{Conclusión}

En este artículo se ha descrito la evolución cultural del ser humano. Se hizo un análisis desde la capacidad comunicativa a la capacidad de abstracción, simbolización e interpretación de la realidad, y el rol que juega la cultura en ese proceso.

A través de algunos ejemplos de estudios etológicos se descubrieron algunos puntos de encuentro -en comunicación y aprendizaje-entre el ser humano y el animal. Sin embargo, también fue posible asentar que lo que caracteriza la comunicación y el aprendizaje humanos es la simbolización y la autorreflexión.
Respecto al estatus moral del ser humano, éste provendría de la capacidad de pensarse a sí mismo y del proceso de diferenciarse y metaobservarse(1) considerando la realidad. El ser humano conoce las cosas cuando las aprehende a través de conceptos y en el proceso de conocimiento de la realidad es cuando se integra la carga de valores, símbolos, signos y significantes que complejizan el proceso de comunicación y van tejiendo la malla cultural.

Empero, a pesar de vivir en una sociedad globalizada altamente tecnificada y compleja, donde la interacción de los sistemas parciales(1) demanda una estructuración de códigos binarios en cada subsistema que interactúa con el entorno, los humanos culturales seguimos teniendo comportamientos aculturales que contradicen los años de evolución y de complejización sistémica, como son la violencia $\mathrm{y}$ el incesto.

\section{Referencias}

1. Luhmann N, Raffaele G. Teoría de la sociedad. México: Triana/U.BEO.ITESO: 1998.

2. Alan M. Biological Anthropology. 2nd edition. EE.UU.: Mayfield Publishing Company:1999.

3. Tylor E. Lo superorgánico. En: Kahn JS, (comp.) El concepto de cultura: textos fundamentales. Barcelona: Anagrama; 1975.

4. Lévi-Strauss C. Las estructuras elementales del parentesco. Buenos Aires: Paidós; 1969.

5. Bateson G. Pasos hacia una ecología de la mente. Buenos Aires: Planeta: Carlos Lohlé; 1991.

6. Saussure F. Lingüística de la lengua y lingüística del habla. Buenos Aires: Losada; 1968.

7. Berger P, Luckmann T. La construcción social de la realidad. Buenos Aires: Amorrortu; 1979.

8. Girard R. La violencia y lo sagrado. Barcelona: Anagrama; 1995.

9. Ricoeur P. La memoria, la historia y el olvido. Buenos Aires: Fondo de Cultura Económica; 2004.

10. Hobbes T. Leviatán. Madrid: Alianza; 1997.

Recibido el 3 de mayo de 2007.

Aceptado el 17 de abril de 2007. 